\title{
Underwater observations of fish behavior in traps
}

\author{
W. L. High \& I. E. Ellis \\ Northwest Fisheries Center, National Marine Fisheries Service; \\ Seattle, Washington, USA
}

KURZFASSUNG: Unterwasserbeobachtungen über das Verhalten von Fischen in Fallen. Im Rahmen des Einsatzes von Unterwasserlaboratorien in den Gewässern vor Florida und in der Karibischen See wurden bei Sätrigungstaucheinsätzen Studien über das Verhalten von Fischen vor Fallen angestellt. Verschiedene Käfigw und Netztypen kamen zum Einsatz und wurden auf ihre Brauchbarkeit zum Fischfang geprïft. Die Verhaltensweisen der Fische vor und innerhalb der benutzten Fanggeräte wurden eingehend verfolgt.

\section{INTRODUCTION}

Beginning in 1970, saturation diving techniques were used in three studies of fish behavior in relation to traps. The first experiments were conducted as part of the "Tektite II Undersea Laboratory Program" in the Virgin Islands (Fig. 1). In December 1971, the second dive utilized the undersea laboratory, Hydro-Lab, located off Grand Bahama Island. The fish trap studies were continued in January 1972 from Edalhab near Miami, Florida.

Saturation diving from the undersea habitats permitted the diving scientists to make in-situ observations and to maximize their underwater observational time. Scientist teams lived in the habitats up to 14 days. They rested, cooked their meals, and slept in the habitats in an artificial pressurized atmosphere of air or mixed gas. To conduct the fish behavioral observations, the aquanauts donned their diving suits and SCUBA gear and left the undersea laboratories to swim around nearby reef areas for periods as long as 8 hours per day. They ventured up to $500 \mathrm{~m}$ from the habitats to accomplish their work.

The underwater experiments compared the fishing effectiveness of traps designed for local fisheries and experimental traps. The diving scientists observed effects on fish of different conditions such as triggers on trap tunnels, various types and sizes of tunnel openings, locations of traps relative to reefs, types of bait, lengths of time traps were fished, and extended trap leads.

\section{EQUIPMENT AND METHODS}

Initially, three kinds of traps were tested, i.e., Virgin Islands commercial, experimental, and plastic. The aquanauts soon discontinued the use of the commercially 
made plastic trap because it was ineffective. Most tests employed the style of traps used by local fishermen in the Virgin Islands, and experimental traps of design similar to sablefish traps developed by the National Marine Fisheries Service in Seattle, Washington.

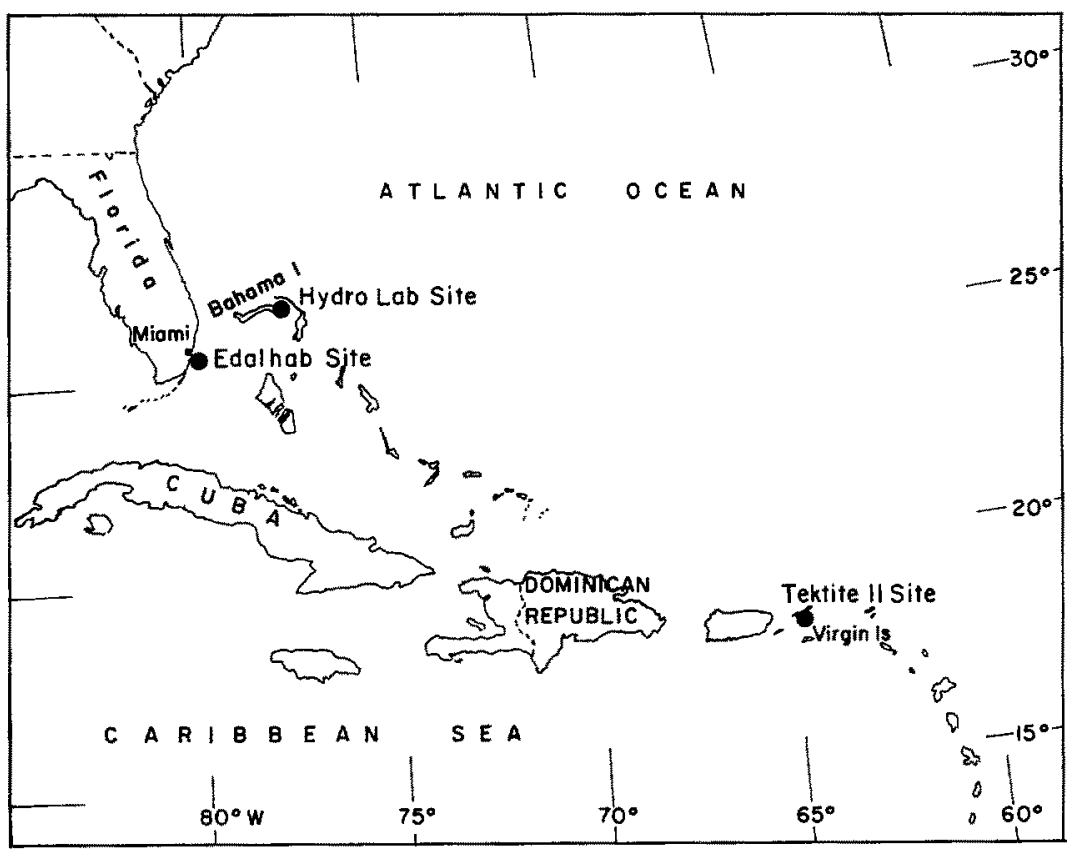

Fig. 1: Sites adjacent to the southeast United States where three saturation diving programs were conducted

Both the Virgin Islands and the experimental traps have been described in detail by High \& BeARDSLEY (1970). The Virgin Islands traps were constructed of wood, covered with chicken wire, and had rigid tunnels. The experimental traps were of web-covered aluminium frames with dimensions of about 1 by 1 by $2 \mathrm{~m}$.

Several trap entrance designs were used to assess their influence on size and species captured. The Virgin Islands trap tunnels of chicken wire were oval in cross section and bent down at the inner end with the trap orifice below. Fish swam into the tunnel, then turned downward to pass through the orifice into the trap interior. Some of the experimental trap tunnels used in the Virgin Islands had spring-loaded steel prongs (triggers) spanning a rigid framed orifice to prevent the escape of large fish. During the Bahama and Florida studies, only experimental traps having web tunnels with either a rigid steel-framed opening or flexible orifices were used. The flexible orifice appeared as a narrow slit about $30 \mathrm{~cm}$ long, usually set horizontally (Fig. 2).

Test baits used during the three studies included cactus, crushed sea urchin, fish meal, conch, and chopped or whole fish. Usually the bait was placed in fine-meshed 
plastic bags. During the third study, small grunts captured in one trap were removed to rigid wire-meshed boxes and used as live bait in other traps. Bait was sometimes left free in the trap where it could be eaten. Some tests were conducted with unbaited traps.

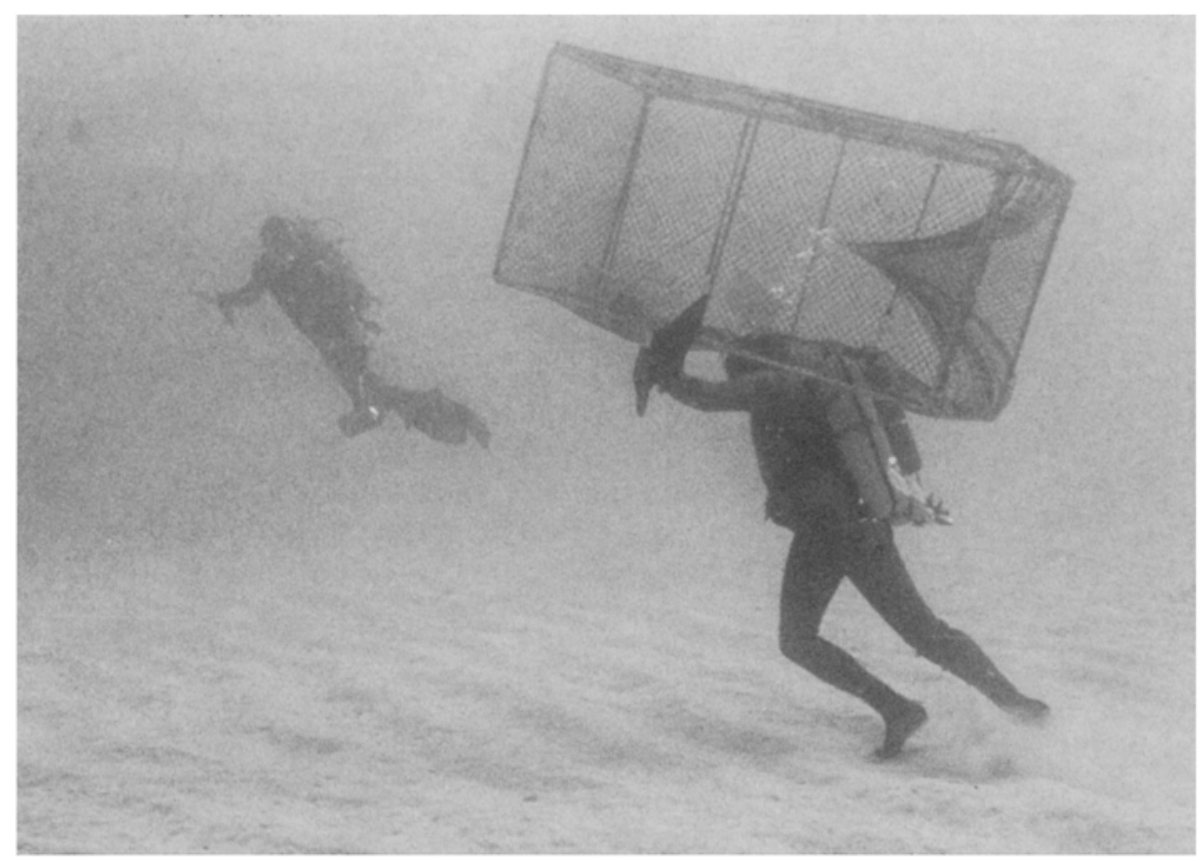

Fig. 2: Underwater view of flexible tunneled experimental trap being moved to a new site

A demersal-net lead was used to herd fish to traps. The lead was a $15 \mathrm{~m}$ long, $2.5 \mathrm{~m}$ high piece of $2.5 \mathrm{~cm}$ stretched-mesh netting. Plastic floats were spaced at $1.3-\mathrm{m}$ intervals along the top of the lead. Plastic bags filled with sand and placed along the net groundline kept it against the ocean floor. The lead was stretched out across a sand flat near Hydro-Lab to intercept the diurnal migration of reef fishes. A trap was placed at each end of the lead.

\section{RESULTS}

\section{$\mathrm{Number}$ of fish caught}

Virgin Islands-style traps captured the greatest number of fish, although the fish were smaller than those captured in experimental traps. Some selectivity was caused by differences in tunnel size and overall trap size; larger fish could not enter the small Virgin Islands-trap orifice and small fish, once inside, tended to remain in the Virgin 
Islands-type traps. Fewer fish were observed entering the experimental traps having $20 \mathrm{~cm}$ square rigid-framed orifices and triggers than those without triggers. Those without triggers had a much higher escape rate.

During the Edalhab studies, experimental traps with the rigid metal-framed orifice captured a greater variety of fish than did the traps with flexible all-web tunnels. However, fish frequently escaped from the traps with the rigid orifice.

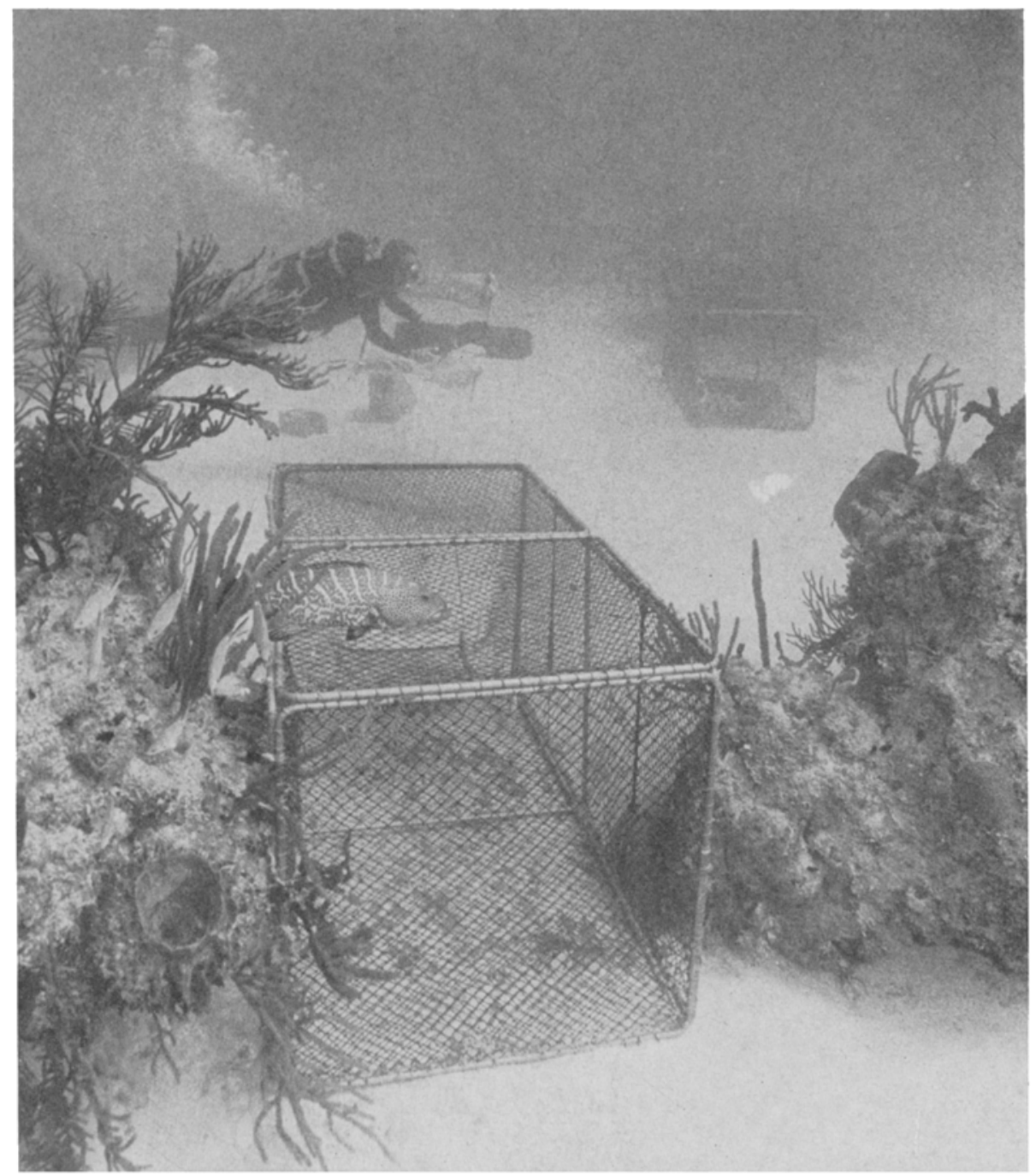

Fig. 3: A moderate-sized grouper is shown inspecting a trap containing several small fish (not shown) placed adjacent to the coral reef. In the background, an aquanaut uses an underwater scooter to tow himself and two small plankton nets 
Fish entering traps through the flexible-web orifice had to physically push through the orifice. However, numerous large ones, including grouper to about $7 \mathrm{~kg}$ and four nurse sharks about $1.8 \mathrm{~m}$ long, were captured. Some tunnels, when adjusted to reduce the force required by small fish to push through, permitted smaller individuals to be captured. Escape from the flexible-web tunnels appeared to be low.

Experimental traps with rigid metal-framed orifices captured as many as four lobsters per night, but none were taken in the Virgin Islands trap or the all-web experimental trap.

Daytime catches were generally higher than those during darkness for the dominant species, including groupers, squirrelfish, and parrotfish. In the Bahama Islands, grunts were the dominant catch, but they were usually taken during the night.

\section{Effect of bait}

Although bait was assumed to play an important role in attracting fish into traps, no differences between bait types were found. Cactus (commonly used by local fishermen in the Virgin Islands), crushed sea urchin, fish meal, conch, and chopped fish all attracted about the same number of fish. Moreover, unbaited traps caught as many fish as baited traps.

During the first two dives, the divers frequently observed that predator species, such as groupers and nurse sharks, were attracted to the traps by frantic escape activities of small captured fish. The predator's presence further frightened the captured fish, which in turn caused the predator to increase its efforts to get into the trap. Once inside, the predator usually ate one or more small fish.

Small fish were therefore confined in wire-mesh boxes and placed inside traps during the third saturation dive. Catches of large fish were not enhanced, apparently because the small fish remained calm within the cages and only a few predator fish were observed in the study area.

\section{Effect of traplocation on $c$ atch}

Catches were greatest when the traps were placed on the sandy ocean floor close to reefs (Fig. 3). One Virgin Islands trap placed on the sand plain $4.5 \mathrm{~m}$ from a squirrelfish congregating area caught five fish, including only one squirrelfish. When the trap was moved to within $2 \mathrm{~m}$ of the coral, catches increased to as many as 25 squirrelfish in 24 hours. Traps placed on top of the reef caught fewer fish than when they were placed alongside the reef.

\section{Net lead}

Small grunts moving onto the sand flats at night were intercepted by the lead. Two nurse sharks entered the trap at one end and ate whatever other fish had already entered the trap. 


\section{Fish behavior in and neartraps}

Behavior of trapped and free fish varied widely. Four-eye butterflyfish and spotted goatfish swam frantically back and forth outside the trap when others of their species were caught. When several grunts were trapped, others appeared attracted by them and swam to the trap. They swam around it with their snouts bumping the walls until they found the tunnel and entered. Small rock hinds sometimes approached a trap and inspected the calm trapped fish. In contrast, squirrelfishes, when trapped, moved around actively in the trap; yet other squirrelfish outside the trap appeared calm and moved slowly.

A trapped nurse shark and one outside the trap were observed for several hours. The trapped shark flailed vigorously, bouncing the trap around. The free shark repeatedly moved around the trap and part way into the tunnel. It repeatedly attempted to push its way beneath the trap and it bit at the web near the tunnel entrance. An examination of the hole it bit in the trap web showed the hole to be identical in appearance and location to those found in web traps on other occasions.

Predatory behavior was common around the traps containing fish. Often when captured grunts swam placidly in the trap, large predators in the vicinity did not respond. When the trapped fish became frantic, darting back and forth in the trap, predator fishes approached quickly and searched for an entrance.

Territorial behavior was frequently exhibited. When more than one large grouper was in a trap, the largest grouper periodically pursued the smaller ones. When trapped, non-predatory parrotfish frequently attacked and killed their own species.

\section{Divers'effecton fish}

A major concern of behaviorists making direct underwater observations is the possible effect of the diver upon the animals under study. Divers are well aware that exhaust bubbles from conventional SCUBA gear may frighten fish. Although most fishes seems to adjust quickly to the diver's presence, it was necessary for him to remain at a greater distance than would have been necessary with rebreathing apparatus that does not exhaust bubbles.

\section{CONCLUSIONS}

There was no apparent single reason why the fish entered the traps. Some probably entered out of curiosity while others apparently reacted to fellow species in distress and, obviously, some entered as predators to capture prey in a confined area. Based upon observations of predator fish seeking small trapped fish, the diving scientists believe an effective trap for large predator fishes, such as groupers, should contain a small inner trap so small fish entering the trap could continue into an area isolated and protected from predator fish entering the trap to feed.

Near-bottom species were intercepted by the trap lead. Observations suggest that its strategic placement along fish migration routes would increase trap catches. 
Direct underwater observations provided data not available to surface-restricted scientists. Underwater researchers were able to work among the reefs for up to 8 hours per day, an effective working time of about four times that of a surface-based diving scientist. However, to most scientists the initial saturation-diving experience is so novel that it is difficult to preplan experiments due to lack of experience and knowledge of the full potential this type of diving offers. Therefore, the scientist becomes a great deal more effective after his first saturation dive.

\section{SUMMARY}

1. Saturation diving from the undersea laboratories Tektite II, Hydro-Lab and Edalhab permitted scientists to conduct extended in situ observations of fish within the influence of traps. The 14,5 and 4 day studies were conducted in the U.S. Virgin Islands, Bahama Islands and Florida during April, 1970, December, 1971, and January, 1972.

2. Virgin Island style traps captured the greatest number of fish, although they were smaller than those captured in experimental traps. Trap entrance design was a major factor in its effectiveness. An ungated web tunnel worked poorly when the orifice slit was drawn tight because fish would not readily push through it. However, when loosened, very large fish entered, including several groupers and $1.8 \mathrm{~m}$ long nurse sharks. Few fish escaped through the Virgin Island trap tunnels, whereas numerous fish were seen swimming from the gated experimental trap tunnels.

3. Cut bait seemed to play a minor role in attracting fish to traps. However, large fish were attracted by escape efforts of smaller trapped fish. Trap location in relation to natural fish aggregating areas or movement routes affected the catch.

4. Numerous behavioral characteristics relating to fishes within the influence of the traps were noted, including territorial defense, social behavior and predator-prey relationships.

\section{LITERATURE CITED}

High, W. L. \& Beardstey, A. J., 1970. Fish behavior studies from an undersea habitat. Comml. Fish. Rev, $32(10), 31-37$.

First author's address: W. L. HigH

Northwest Fisheries Center

National Marine Fisheries Service

2725 Montlake Blvd. East

Seattle, Washington 98112

USA 